\title{
Employing the Model Based Systems Engineering Methodologies to Develop a Domain Specific Language for Contracting of Infrastructure Projects
}

\author{
Farid Shirvani, Peter Campbell, Ghassan Beydoun, William Scott \\ SMART Infrastructure Facility, University of Wollongong, \\ Farids@uow.edu.au
}

\section{Introduction}

Infrastructure typically characterises technical structures such as transport systems (roads, bridges, tunnels, etc.), water supply, sewers, electrical grids, telecommunications, and so forth [1], and can be defined as the physical components of interrelated systems providing commodities and services essential to enable, sustain, or enhance societal living conditions [2]. Therefore infrastructure is inherently a set of interrelated systems, also known as a system of systems (SoS), that aims to provide services to the public, and ultimately makes the Government liable for the availability and quality of those services. Projects defined to acquire such systems are costly, long and complex to manage. The procurement context is comprised of many organizations with different concerns; each plays a particular role in this collaborative scenario, having many interactions to other roles, which further makes the procurement complex and entangled. Since the government is responsible for managing these projects, the Public Private Partnership (PPP) has been recently gained attention from the government as the procurement method for infrastructure system. In PPP the public sector is responsible for establishing performance standards and ensuring that the concessionaire meets them. In essence, the public sector's role shifts from being the service provider to regulating the price and quality of service [3].

Governments publish the rules of procurements in various documents to regulate the procurement context. Despite the completeness and expressiveness of the PPP guideline documents, which are written in natural languages, there exist many problems regarding understanding, interpreting and consistent application of these rules. Moreover, responding to the "Request for Proposals" issued by governments involves generating a large amount of documents by bidders which introduces complexity and costs to the bidding, bid evaluation and negotiation processes. Local governments often lack the staff needed to plan, negotiate and monitor a contract that is suited to local circumstances and must spend significant resources acquiring the expertise and advice required. A 2007 report from the UK National Audit Office [4] found that the average cost of external advice in procuring Private Finance Initiative deals was just over $£ 3$ million per project. In Cornwall, Ontario, the local paper [5] reported mounting costs associated with procuring a recreation centre as a PPP. Costs included $\$ 95,000$ to Ernst \& Young for services related to the project, including preparing documents and exploring the possibility of a PPP, as well as $\$ 125,000$ to a Toronto law firm for help preparing the agreements and documents required in a PPP deal. In Halifax the consultant fees associated with preparing an RFP for a four-pad arena came to $\$ 128,640[6]$.

In this study we employ the Model Based Systems Engineering (MBSE) methodologies and tools to address the problems raised from document centric engineering. MBSE "is the formalized application of modelling to support system requirements, design, analysis, verification, and validation activities beginning in the conceptual design phase and continuing throughout development and later life cycle phases" [7]. MBSE is intended to facilitate systems engineering activities that have traditionally been performed using the document-based approach and result in enhanced communications. [8]. According to the studies on MBSE since 2006 [8] [9] [10] [11] [12], practicing MBSE involves six fundamentals: Process Standard, Systems Engineering Method, Architecture Framework (AF), Architecture Description Language (ADL), Model and data exchange standard, and modelling tool.

The Architecture Frameworks that are discussed in this paper are the acquisition oriented AFs. The acquisition AFs are developed by the defence sectors in the form of metamodels to provide a standardized knowledge structure for information sharing. These metamodels generate the consistent and integrated models of both the 'system' and the 'acquisition project' defined to acquire the system. DoDAF (Department of Defense Architecture Framework) is an example of acquisition AF. UML (Unified Modelling Language) and SysML (Systems Modelling Language; a UML profile) are the ADLs often used to model AF artefacts.

Our previous studies [13] have analysed the Architecture Frameworks to assess their adequacy and effectiveness in modelling the acquisition projects. The results show that the system specific concerns such as user requirements, system services, physical and functional aspects of the system are fully or partially covered by the current architecture frameworks (DoDAF, MoDAF, TRAK). However, the concerns related to the 'procurement 
of the system' such as financial aspects of the project, project risks, bid evaluation and asset ownership are mainly overlooked. So, the next step of this research, which is summarized in this paper, focuses on expanding the architecture frameworks to make them capable of covering all aspects of the procurement projects. Since this expansion should be integrated to all the AFs, we have picked UPDM [14] (Unified Profile for DoDAF and MoDAF) as the internationally accepted and academically registered profile for the mentioned AFs.

This paper focuses on identifying the procurement concerns and adding new viewpoints to the architecture frameworks; and developing a domain specific language based on SysML to be served as the ADL to model the new viewpoints. It is organised as follows: the proposed solution is explained in section 2 . Section 3 briefly describes the methodology used for creating the metamodel and the language. Some samples of the achieved results are provided in section 4 and finally, section 5 draws the paper conclusion.

\section{Proposed Solution}

In order to extend the Project/Acquisition viewpoints of UPDM, three enhancements will be made: identifying the views to depict common information needed for procurement, an expansion of the metamodel to the procurement domain, and finally the language necessary to populate these views. Figure 1 illustrates how this DSL fits into the context of current literature. As shown, UPDM consists of a metamodel (abstract syntax) which is mapped to a profile (concrete syntax). The UPDM profile is a group of stereotypes which are specializations of UML and SysML. Likewise, the DSL has a metamodel that expands the UPDM metamodel (adds new concepts to it); and is mapped to a profile which is specializations of (i.e. extends) SysML.

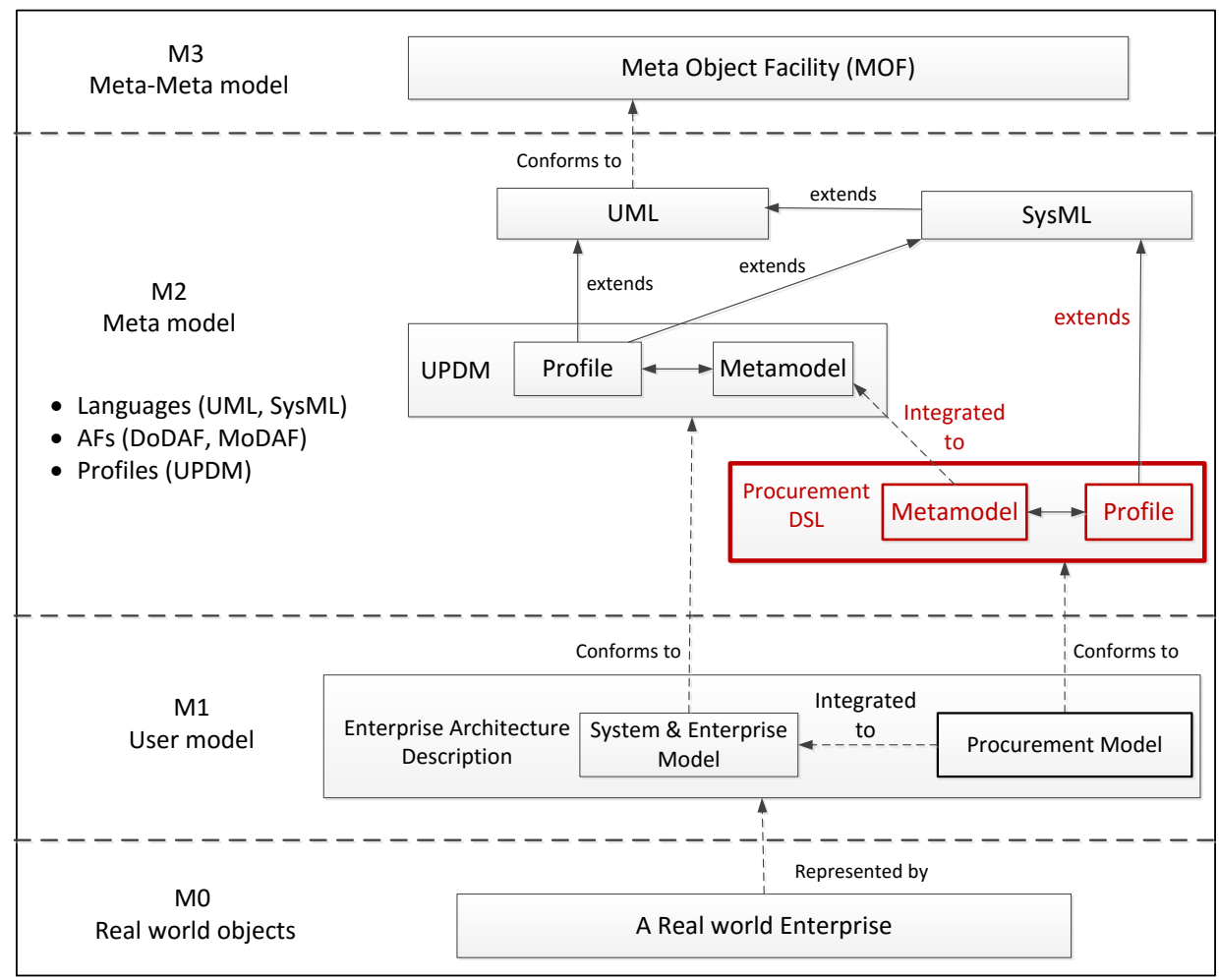

Figure 1: Putting the research deliverable into the context of existing literature

\section{Methodology}

The Domain Meta Model (DMM) of the procurement domain will be created as an 'abstract syntax' of the new viewpoints. Then the created metamodel should be integrated to UPDM to assure the integrity between the models generated by each of the metamodels. The concepts of the DMM will be mapped to SysML elements so that the 'concrete syntax', which is the interface between the AF metamodel and the modeller, will be created as a SysML profile. This profile consists of stereotypes that are specializations of SysML elements (e.g. 'risk' is a specialization of SysML 'Block'). The 'constraint rules' of the metamodel will also be written in OCL (Object Constraint Language). Finally, the stereotypes will be grouped, according to the viewpoint they are representing, 
to create new SysML diagram frames. These new SysML diagrams all together form a Domain Specific Language (DSL) which will be used for modelling the procurement projects. The methodology is shown in more details in Figure 2.

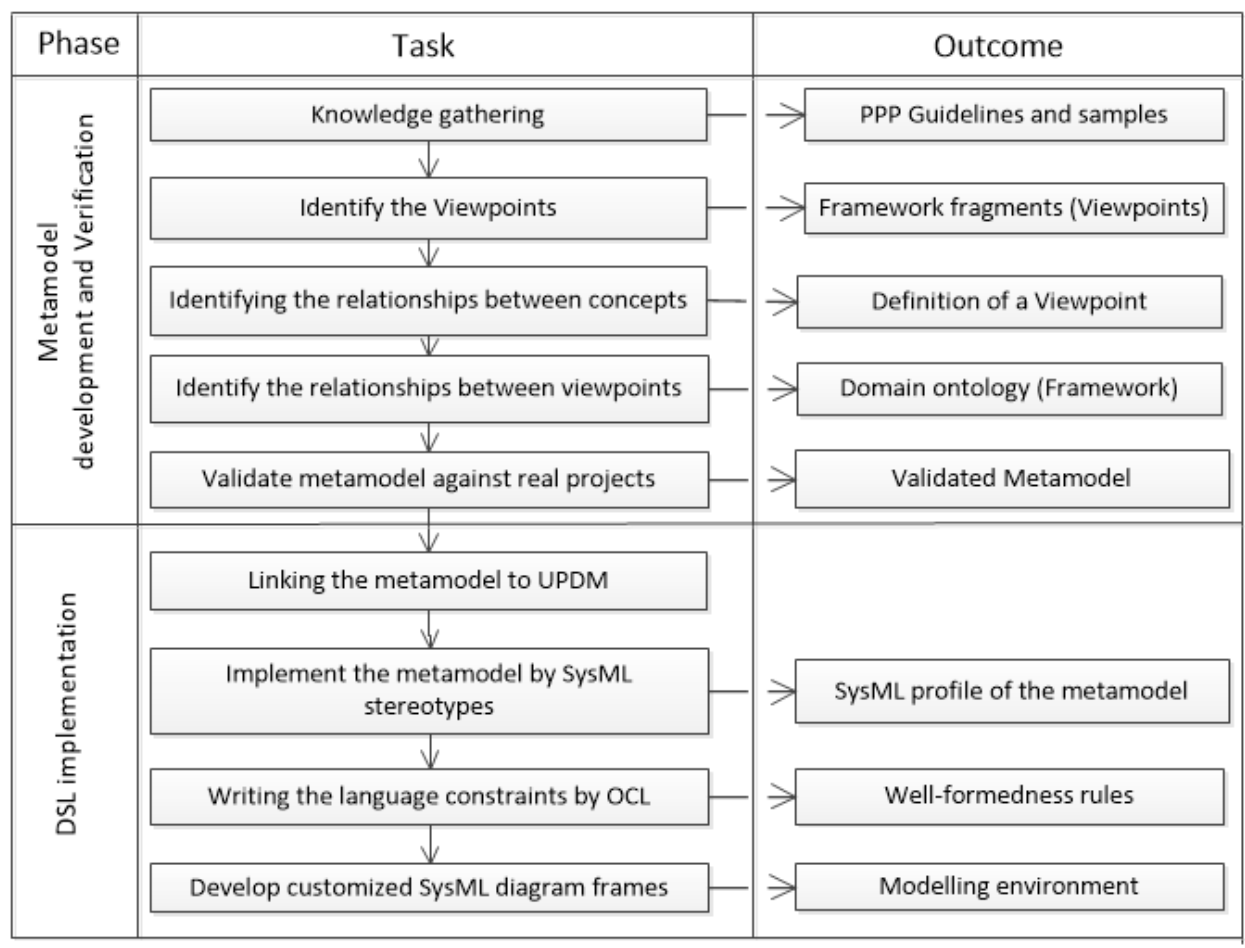

Figure 2: Method of developing the Metamodel and the Language

\section{Results}

In the knowledge gathering step, the PPP frameworks and guidelines were collected from the infrastructure departments and regulatory agencies of a variety of countries including Australia, UK, South Africa, India, Hong Kong and Singapore.

\subsection{Domain Structuring and Viewpoint identification}

As shown in Figure 3 the structure of PPP domain is created according to the gathered knowledge. The PPP has 6 stages and each stage consists of some parts or viewpoints. In order to create a metamodel for PPP, each viewpoint (metamodel fragment) should be defined and then the combination of these fragments will form the PPP metamodel.

\subsection{Sample viewpoints}

In this section, two of the mentioned viewpoints, Project Organizations and Risk Evaluation, are chosen as exemplars to show their structure and how they produce the models.

\subsubsection{Project Organizations}

One aspect in initializing the project is identifying the involved organizations and their relationships. This viewpoint allows the modeller to choose from a variety of typical organizations that play a role in the project and link them to each other. Figure 4 shows the typical organizations and Figure 5 illustrates how these stereotypes have formed a diagram by which the modeller creates the arbitrary models of these relationships. 


\begin{tabular}{|c|c|}
\hline Stage 0: Project Principals & $\begin{array}{l}\text { Viewpoints: } \\
\text { 1. Project Organizations } \\
\text { 2. Project Funding }\end{array}$ \\
\hline Stage 1: Project Appraisal & $\begin{array}{l}\text { Viewpoints: } \\
\text { 1. Project costs } \\
\text { 2. Project Revenue (Demand modelling) } \\
\text { 3. Feasibility (Environmental, Technical) } \\
\text { 4. Value for Money }\end{array}$ \\
\hline Stage 2: Project Structuring & $\begin{array}{l}\text { Viewpoints: } \\
\text { 1. Risk Identification } \\
\text { 2. Risk evaluation } \\
\text { 3. Risk allocation }\end{array}$ \\
\hline Stage 3: Project Design & $\begin{array}{l}\text { Viewpoints: } \\
\text { 1. Performance requirements (output services) } \\
\text { 2. Payment mechanism } \\
\text { 3. Dispute resolution } \\
\text { 4. Termination provision }\end{array}$ \\
\hline Stage 4: Tendering Transactions & $\begin{array}{l}\text { Viewpoints: } \\
\text { 1. Expression of Interest } \\
\text { 2. Request for Proposals } \\
\text { 3. Bid Evaluation }\end{array}$ \\
\hline Stage 5: Project Management & $\begin{array}{l}\text { Viewpoints: } \\
\text { 1. Management structure } \\
\text { 2. Management responsibilities }\end{array}$ \\
\hline
\end{tabular}

Figure 3: PPP Stages and identified Viewpoints

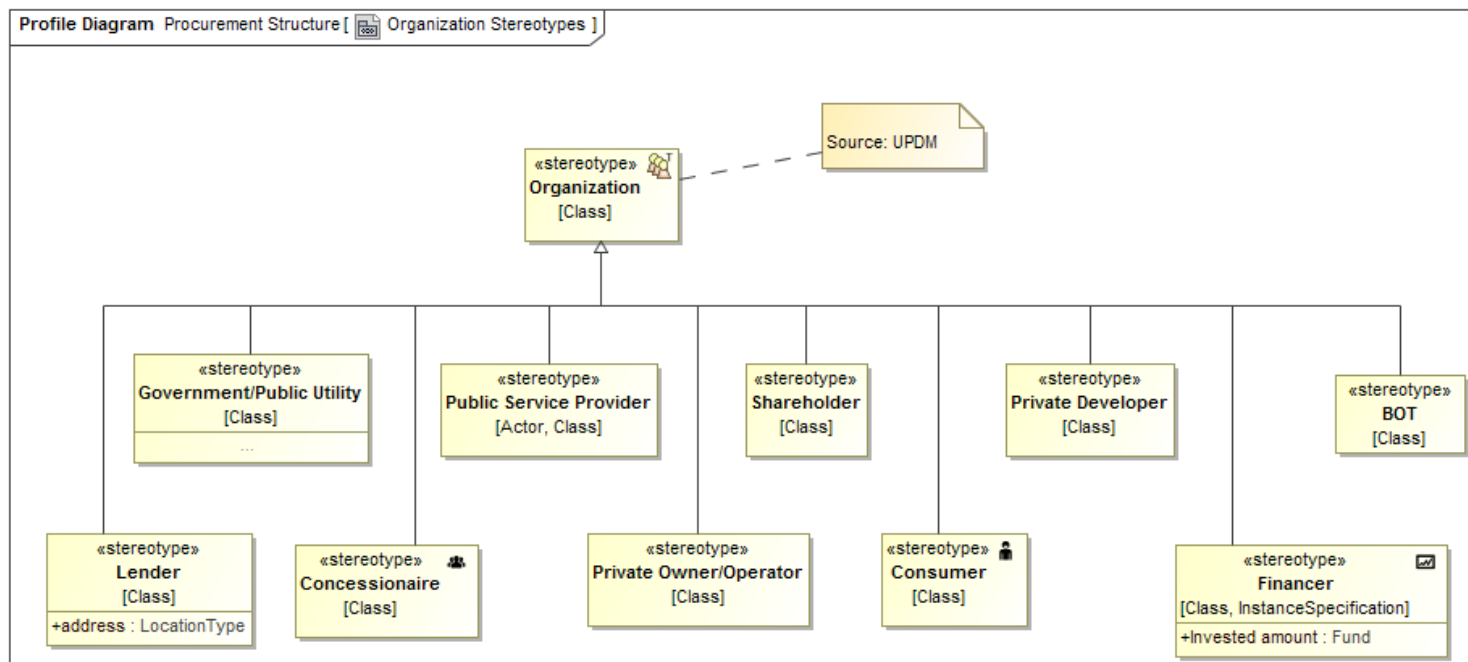

Figure 4: Organization Stereotypes 


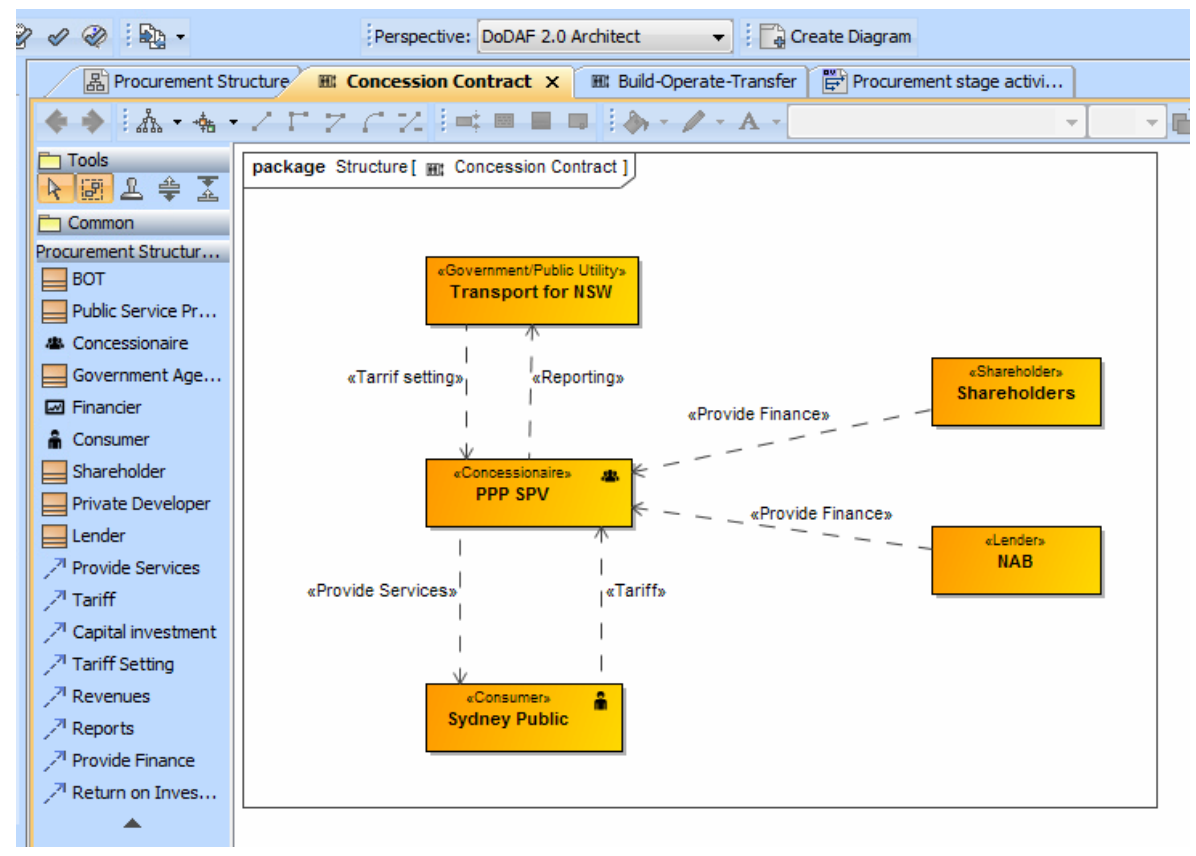

Figure 5: Organization Relationship Diagram

\subsubsection{Risk Assessment}

This viewpoint is defined to accommodate the project risks and prioritizing them by indicating their likelihood and severity of their consequences. Figure 6 illustrates the concepts of this viewpoint and Figure 7 shows a sample of a risk assessment diagram.

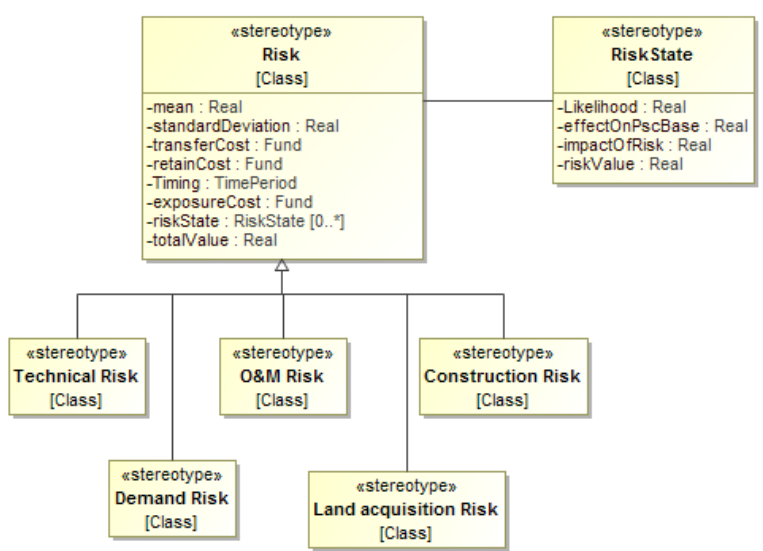

Figure 6: Risk Stereotypes

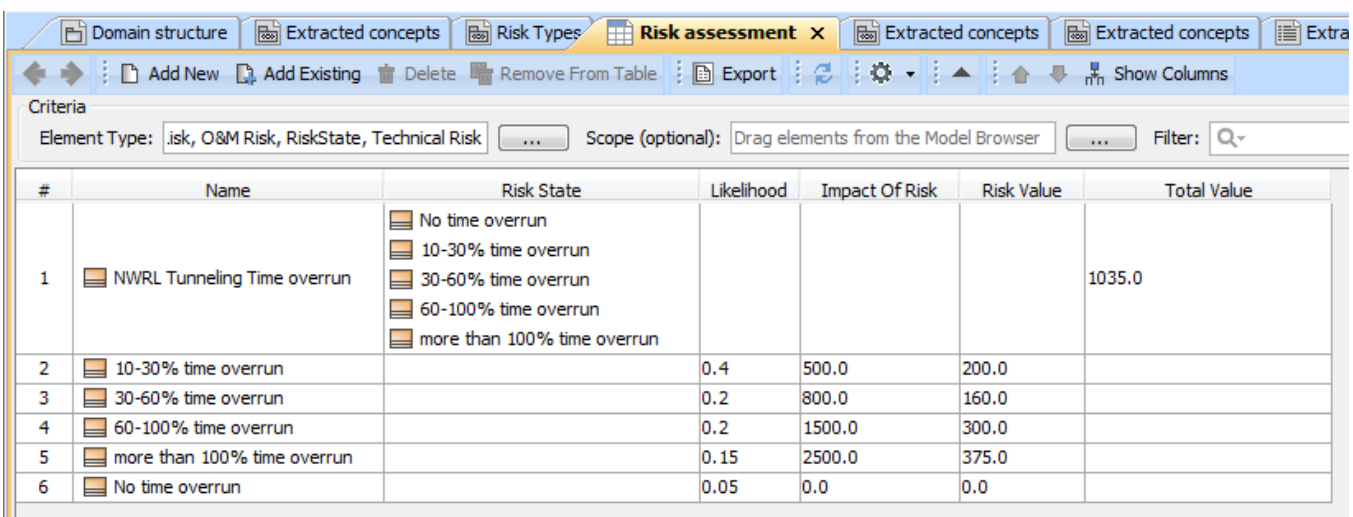

Figure 7: Risk Assessment Diagram 


\section{Conclusion}

This paper focuses on improving the Architecture Frameworks to increase their capability in modelling the procurement projects of infrastructure systems. The solution is proposed as a Domain Specific Language for infrastructure procurement. The methodology is provided which shows how the metamodel (abstract syntax) and the language stereotypes (concrete syntax) are developed. The results firstly show the 18 identified viewpoints of procurement domain and then chooses 2 of them as examples. The Project Organization Viewpoint and Risk Assessment Viewpoint and the models they generate are shown. In the next step of this study, all other 16 viewpoints will be created to provide a full modelling language for infrastructure procurement. This DSL can be used by the domain practitioners, who are the contracting officers and procurement managers, to generate the contracting materials to facilitate the contracting process, assure the consistency of the procurement documents, giving better project outcomes.

\section{References}

1. Arthur Sullivan and Steven M. Sheffrin, Upper Saddle River, in Economics: Principles in action. 2003, New Jersey 07458: Pearson Prentice Hall. p. 474.

2. Jeffrey E Fulmer What in the world is infrastructure? PEI Infrastructure Investor, 2009.

3. Department of Infrastructure and Transport, Infrastructure Planning and Delivery: Best Practice Case Studies Volume 2, Infrastructure and Transport, Editor. 2012, Department of Infrastructure and Transport

4. National Audit Office, Improving the PFI Tendering Process. 2007: London: Stationery Office. p. 5.

5. Standard Freeholder, Arena Expenses Climb Past \$300,000 ... and Counting. 2008.

6. Paul Dunphy, Information Report, Submitted to Mayor Kelly and members of Halifax Regional Council, Halifax Regional Municipality, Editor. 2009, Community Development: Community Development.

7. SE Handbook Working Group, ed. Systems Engineering Handbook v. 3.2.2. ed. Cecilia Haskins. 2011, INCOSE: San Diego, CA 92111-2222.

8. Sanford Friedenthal, Alan Moore, and Rick Steiner, A practical guide to SysML. 2009: Object Management Group (OMG).

9. Jeff A Estefan, Survey of Model-Based Systems Engineering (MBSE) Methodologies, MBSE Initiative International Council on Systems Engineering (INCOSE), Editor. 2008, INCOSE: 2150 N. 107th Street, Suite 205, Seattle, WA 98133-9009.

10. Matthew Hause, The SysML Modelling Language, in Fifth European Systems Engineering Conference. 2006.

11. Jon Holt, Claus Ballegaard Nielsen, Finn Overgaard Hansen, Alvaro Miyazawa, Richard Payne, Juliano Iyoda, and Marcio Cornelio, Initial Report on SoS Architectural Models, in Comprehensive Modelling for Advanced Systems of Systems, Simon Perry, Editor. 2012: COMPASS.

12. Lenny Delligatti, SysML Distilled: A Brief Guide to the Systems Modeling Language. 2014, New Jersey: PearsonEducation, Inc.

13. Farid Shirvani, Mahmoud Efatmaneshnik, and Peter Campbell, An Architecture Framework Modification Supporting the Acquisition Stakeholders, in Systems Engineering Test and Evaluation. 2014, SETE Proceedings Adelaide.

14. OMG, Unified Profile for DoDAF and MODAF (UPDM) V 2.1. 2013. 